\title{
Distant blunt forceps dissection in tissue expander insertion: A novel technique
}

\author{
Oren Weissman MD¹, Gabriel Hundeshagen $M D^{2}$, Jonathan Bank MD³ , Isaac Zilinsky MD , \\ Efrat Solomon $M D^{1}$, Eric Remer $M D^{1}$, Guy Rasner $M D^{1}$, Josef Haik MD MPH ${ }^{1}$
}

O Weissman, G Hundeshagen, J Bank, et al. Distant blunt forceps dissection in tissue expander insertion: A novel technique. Plast Surg 2016;24(3):174-176.

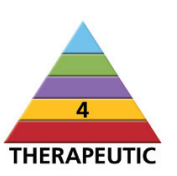

Tissue expansion using implantable expanders is a useful means of generating surplus tissue for reconstruction of defects such as scarring following burns. The authors describe their technique of incisions distant to the desired location of expander placement, and remote dissection of the expander pocket with hydrodissection and blunt forceps. A total of 81 expanders were placed in 30 consecutive patients, $81 \%$ of whom had burn scars due for reconstruction. During preparation, no complications, such as bleeding, were encountered, except one case with severe subdermal fibrosis, in which bleeding was stopped through brief application of pressure. Postoperatively, no complications were encountered in $76 \%$ of patients; however, $16.6 \%$ exhibited surgical site infection, which was managed conservatively and was correlated with a high number of expanders implanted at once. One patient experienced hematoma formation that resolved spontaneously, and one instance of expander extrusion and subsequent removal occurred. Receiving $\geq 2$ expanders at the same time was statistically associated with higher risk for complication(s). The authors' complication rates were moderate and comparable with open or endoscopic approaches. Time of expansion is reduced compared with the open approach due to distant incision placement and immediate usability. Cost effectiveness appeared to be better using only inexpensive forceps, rather than elaborate and costly endoscopic equipment.

Key Words: Hypertrophic scarring; Minimally invasive technique; Postburn reconstruction; Tissue expansion

\section{La dissection à distance par pinces mousse pour insérer des expanseurs tissulaires : une nouvelle technique}

L'expansion tissulaire à l'aide d'implants produit un excédent de tissus utile pour reconstruire des lésions telles que des cicatrices consécutives à des brûlures. Les auteurs décrivent leur technique d'incisions éloignées du foyer de l'expanseur et leur méthode d'hydrodissection par pinces mousse à distance de la poche d'expanseur. Au total, ils ont inséré 81 expanseurs chez 30 patients consécutifs, dont $81 \%$ pour reconstruire des cicatrices consécutives à des brûlures. Pendant la préparation, les chercheurs n'ont relevé aucune complication, telle qu'une hémorragie, à part un cas d'importante fibrose sous-cutanée dont l'hémorragie a été interrompue par une brève pression. Après l'opération, ils n'ont observé aucune complication chez $76 \%$ des patients, mais $16,6 \%$ ont présenté une infection au site chirurgical, liée à l'implantation de plusieurs expanseurs en une même intervention et traitée avec prudence. Un patient a présenté un hématome qui s'est résolu spontanément, et un autre, une extrusion de l'expanseur qu'il a fallu retirer. L'implantation simultanée d'au moins deux expanseurs s'associait statistiquement à un risque plus marqué de complication(s). Le taux de complications des auteurs était modéré et comparable à celui des chirurgies ouvertes ou des endoscopies. L'expansion était de plus courte durée que par chirurgie ouverte, grâce à l'incision à distance et à l'utilisabilité immédiate. Le rapport coût-efficacité semblait supérieur au moyen de pinces bon marché que de matériel endoscopique élaboré et coûteux.
$\mathrm{T}$ issue expanders have been in use for $>50$ years, and have emerged as an important tool for harvesting tissue and other purposes (1). Tissue expanders are especially useful in patients with extensive tissue damage, such as burns, for which a shortage of donor tissue is common. In these patients, this technique can produce large autografts or flaps that have tissue characteristics in terms of colour, innervation and texture similar to the recipient site (2). In fact, this modality holds significant reconstructive benefits despite certain drawbacks. Common complications associated with tissue expansion techniques include infections, early and late formation of seromas and hematomas in the expander pocket, and extrusion of the tissue expander, usually necessitating its removal (3). Furthermore, actual wound healing following the expander insertion surgery itself can delay tissue expansion and may increase overall morbidity (4).

Several methods are currently used to mitigate some of these drawbacks. Insertion of a balloon expander via a remote incision and using endoscopic techniques for the placement of the expanders is one alternative that has been shown to decrease postoperative complications. A more recent study that investigated the endoscopic approach demonstrated reduced time of expansion, time of hospitalization and patient discomfort (5). However, the costs and technological requirements associated with this technique are significant, which is a limiting factor in its widespread adoption.

In the present study, we introduce a simple and swift method of tissue expander pocket dissection and insertion using curved blunt forceps as an alternative technique to open and endoscopic approaches.

\section{Surgical technique}

\section{METHODS}

All patients underwent thorough preparation and planning of incision placement and desired location and type of expander depending on the individual reconstructive objective. In each case, before the initial incision, hydrodissection of the relevant plane (between subdermal fat and fascia) in the surgical site was performed using the tumescent technique (6): lidocaine $2 \% 10 \mathrm{~mL} / 500 \mathrm{~mL}$ saline $+1 \mathrm{mg}$ adrenaline was injected into the desired expander insertion site, the port tunnel and the desired expander pocket. Following hydrodissection, a short incision was made perpendicular to the intended main axis of the expander, remote from the site of the desired expansion. Whenever possible, the periphery of a pre-existing scar was used for the incision. In doing so, inconceivable incision placement could be achieved without having to directly undermine scar tissue. Following the incision,

${ }^{1}$ Chaim Sheba Medical Center at Tel HaShomer, Department of Plastic and Reconstructive Surgery, Tel Aviv, Israel; ${ }^{2}$ Shriners Hospital for Children - Galveston 815 Market Street, Texas; ${ }^{3}$ University of Chicago Medical Center, Department of Plastic and Reconstructive Surgery, General Surgery, Chicago, Illinois, USA; ${ }^{4}$ The Israeli Association of Aesthetic Plastic Surgeons Fellowship Program, Tel Aviv, Israel Correspondence: Dr Gabriel Hundeshagen, Shriners Hospital for Children - Galveston 815 Market Street, Texas 77550, USA.

Telephone 409-457 6753, e-mail gabrielhundeshagen@gmail.com 


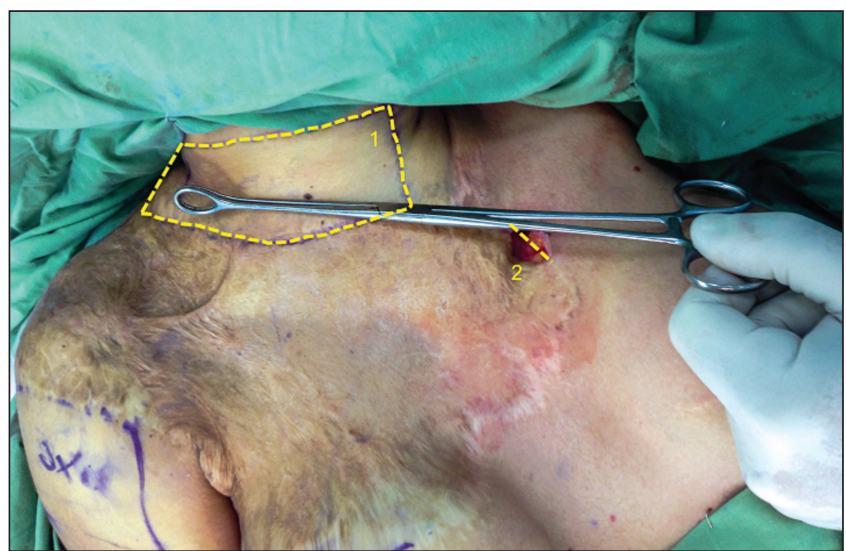

Figure 1) Severe postburn scarring of upper chest and left shoulder. 1 Desired area of expander placement $(12 \mathrm{~cm} \times 7 \mathrm{~cm}) .2$ Remote skin incision for pocket dissection and expander placement. Krauze forceps are able to bridge the distance from incision to remote corner of expander pocket

curved blunt forceps (Figure 1), also termed Rampley's forceps, were inserted and advanced in a closed configuration into the previously hydrodissected plane immediately above the fascia, producing a closed tunnel (Figure 2). At the site of the desired expansion, the blunt forceps were opened in either the horizontal or vertical axis to dissect the plane of insertion. Afterward, the forceps were moved in the horizontal plane from one end of the pocket to the other while ensuring that all septa were left dissected before expander insertion. On completion of pocket dissection, the expander was inserted in a rolled, cigar-like configuration through the small incision site. The tissue expander's port was placed in a separate pocket and secured in place with a single suture by folding subcutaneous tissue around it to prevent sliding or migration of the port to the expander. On completion of positioning, the first saline expansion bolus was injected into the expander through the port until desired expansion was achieved. If more than one expander was placed thorugh the same incision, separated individual pockets were created through the same tunnel.

Subsequent saline injections were then conducted every two weeks during ambulatory visits to a hospital outpatient clinic to facilitate tissue expansion. Due to distant incision placement, injections could be started few days after surgery.

\section{RESULTS}

Insertion of expanders was performed in a total of 30 patients, using a total of 81 expanders. The mean expander size was $471 \mathrm{~mL}$ (range $70 \mathrm{~mL}$ to $750 \mathrm{~mL}$ ). Patient ages ranged from five to 62 years (mean 22.53 years), $17(56 \%)$ were female and $13(44 \%)$ were male. The majority $(83 \%)$ of patients presented with burn scars with subsequent scarring and contractures, requiring tissue expansion to provide adequate skin and soft tissue coverage. Three children underwent excision of giant cell nevi, which left substantial tissue defects. The majority of expanders were placed on the chest and abdomen, followed by the neck, scalp and extremities (Table 1). The mean distance between incision and expander pocket was $6.5 \mathrm{~cm}$ (range $3 \mathrm{~cm}$ to $10 \mathrm{~cm}$ ).

During blunt dissection, the authors did not encounter complications, such as bleeding, from the port tunnel and expander pocket in all but one patient. In this case, severe fibrosis of subcutaneous tissue made the use of sharp scissors necessary, which presumably caused intraoperative bleeding. The complication was managed by applying pressure and subsided thereafter. The first expansion could be performed intraoperatively in all 30 cases and all 81 expanders. Followups for expansions were completed in an outpatient setting.

Postoperatively, no complications were encountered in 23 (76.6\%) cases. Five (16.6\%) patients showed signs of surgical site infection or wound healing problems. In the cases of infection, seven expanders had been placed in one case; in two cases, six expanders had been

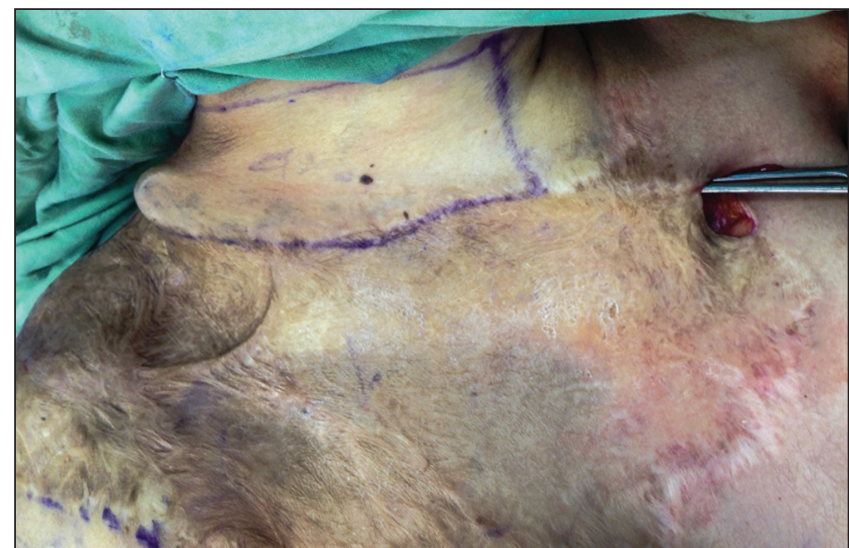

Figure 2) Blunt dissection of expander pocket using Krauze forceps following hydrodissection

placed; and in one case each, three and two expanders, respectively, had been placed at the same time. These complications were successfully treated conservatively and left the tissue expanders unaffected. One patient each $(3.3 \%)$ experienced hematoma formation and expander extrusion and subsequent removal, respectively. Patients who received $>2$ expanders at once were at higher risk for encountering any postoperative complication than those who received one or two expanders at the same time ( $71.4 \%$ versus $9.5 \%)$.

\section{DISCUSSION}

Tissue expansion has been shown to be an effective, safe and well established means of generating additional soft tissue and skin for plastic and reconstructive surgery purposes all over the body (7). While advantages of tissue expansion are tremendous, there are certain drawbacks and possible complications. When inserting the expander into its pocket, most established techniques use incisions, which are close to the actual pocket, which favours pocket preparation and expander handling under direct vision, as well as intraoperative hemostasis. However, healing of this primary incision delays the actual expansion for 10 to 14 days (7). Furthermore, dehiscence of the primary incision has been shown to be the most frequent cause of expander extrusion (4). Hence, there have been efforts to locate the incision further away from the expander pocket, while preserving the benefits of operating under direct vision. Sharobaro et al (5) suggested creating the pocket and placing the expander through a distant, small incision under endoscopic vision. They were able to accomplish shorter expansion time, low complication rates, and excellent wound healing of primary and postreconstructive wounds, demonstrating the benfits of distant incision placement.

The current study showed that the benefits of minimally invasive techniques are preserved in our variation of the procedure. The use of blunted curved forceps (ie, Rampley's forceps) helped us to achieve several objectives. First, the instrument is long, which coincided with our purpose of producing a remote insertion site from the site of expansion. Moreover, its blunted edges provide an ideal tool for dissection of fascial planes, minimizing bleeding compared with regular scissors. Hydrodissection via the tumescent technique helped greatly in establishing the correct plane of dissection, minimizing bleeding, postoperative pain and hematoma formation.

Common complications of tissue expansion include seromas, hematomas, extrusions and infections (3). While our overall complication rates are comparable with those reported in the literature of open approaches, we found lower rates of hematoma formation and expander extrusion than in open or endoscopic approaches $(4,8,9)$. We hypothesize that the low incidence of hematoma of only one in 30 procedures is explained, in part, by the combination of tumescent hydrodissection and blunt dissection and, furthermore, postulate that this technique helps preserve and circumvent skin-perforating vessels, thus decreasing the incidence of hematomas. Additionally, the initial 
TABLE 1

Patient data and outcomes in the present study

\begin{tabular}{|c|c|c|c|c|c|}
\hline Age, years & Sex & Indication & $\begin{array}{l}\text { Location of tissue } \\
\text { expander }\end{array}$ & $\begin{array}{c}\text { Tissue } \\
\text { expanders, } n\end{array}$ & Complications \\
\hline 22 & Female & Postburn scarring & Abdomen & 2 & None \\
\hline 7 & Female & Giant congenital nevus resection & Abdomen & 2 & None \\
\hline 16 & Female & Postburn scarring & Abdomen, neck & 6 & Wound healing problems \\
\hline 15 & Male & Postburn scarring & Back, chest, hand, waist & 7 & Wound dehiscence \\
\hline 21 & Female & Postburn scarring & Back & 6 & None \\
\hline 13 & Male & Giant congenital nevus resection & Abdomen & 1 & None \\
\hline 26 & Female & Postburn scarring & Abdomen & 2 & None \\
\hline 18 & Female & Giant congenital nevus resection & Abdomen & 2 & None \\
\hline 27 & Female & Postburn scarring & Back, shoulder & 6 & Surgical site infection \\
\hline 33 & Male & Postburn scarring & Neck, cheek & 6 & Expander extrusion and subsequent removal \\
\hline 19 & Male & Postburn scarring & Scapular area & 2 & None \\
\hline 9 & Female & Postburn scarring & Scalp & 2 & None \\
\hline 7 & Female & Postburn scarring & Chest & 2 & None \\
\hline 38 & Female & Postburn scarring & Arm & 2 & None \\
\hline 19 & Male & Postburn scarring & Shoulder & 1 & None \\
\hline 10 & Female & Postburn scarring & Abdomen, thigh & 2 & Surgical site infection \\
\hline 16 & Male & Postburn scarring & Shoulder, chest & 3 & Surgical site infection \\
\hline 16 & Female & Postburn scarring & Chest & 2 & None \\
\hline 5 & Male & Postburn scarring & Abdomen & 2 & None \\
\hline 20 & Female & Postburn scarring & Abdomen & 2 & None \\
\hline 62 & Male & Skin tumour (benign) resection & Scapular area & 2 & Postoperative hematoma formation \\
\hline 24 & Male & Postburn scarring & Scalp & 2 & None \\
\hline 27 & Male & Postburn scarring & Neck & 2 & None \\
\hline 14 & Female & Postburn scarring & Neck & 2 & None \\
\hline 20 & Female & Postburn scarring & Scalp & 2 & None \\
\hline 30 & Male & Postburn scarring & Shoulder & 2 & None \\
\hline 17 & Female & Postburn scarring & Neck via facelift incision & 1 & None \\
\hline 21 & Male & Postburn scarring & Waist & 2 & None \\
\hline 23 & Male & Abdominal wall deficiency $d / t$ giant $\mathrm{POVH}$ & Abdomen & 4 & None \\
\hline 21 & Female & Postburn scarring and alopecia & Scalp & 2 & None \\
\hline
\end{tabular}

d/t Due to; POVH Postoperative ventral hernia

intraoperative expansion itself may aid in preventing hematoma formation through a tamponade effect within the expander pocket. It is notable that in our series, the majority of patients presented with extensive scarring caused mostly by burns. In this population, there are higher rates of expander extrusion or wound dehiscence reported (2). Placing $>2$ expanders at the same time and through the same incision increased the individual risk for occurrence of complications. This may be due to the fact that although for each expander a seperate pocket is created, the same tunnel is used for insertion and advancement of forceps and expanders, which may lead to increased rates of contamination, tissue damage and the resulting complications such as infection and hematoma formation. We observed this particular correlation in our patient cohort because most patients who experienced infection, wound healing problems or extrusion recieved a placement of $\geq 6$ expanders simultaneously. This finding needs to be validated in a more comprehensive, prospective and controlled study, and may implicate a limited indication for our approach concerning the number of expanders that can be placed at once.

Although a large study assessing cost effectiveness has yet to be conducted, it is reasonable to assume that minimally invasive techniques using endoscopy require equipment, which is less readily available and requires extra training and maintenance, thus rendering the procedure more costly than the approach described here. Hence, our approach appears to combine the practicability and safety of the open approach with the benefits of minimally invasive distant incision placement. Overall, the technique may contribute to minimizing expansion time and dehiscence of incisions with resulting extrusion of expanders, while being safe and cost effective at the same time.

experience of endoscopic implantation of tissue expanders in plastic and reconstructive surgery. Surg Endosc 2004;18:513-7.

6. Solomon MP. Tumescent technique as an adjunct to breast implant removal and capsulectomy. Ann Plast Surg 2000;44:495-7.

7. Swenson, RW. Tissue expansion: Technique and application. Head Neck Surg 1993;4:61-4.

8. Cunha, MS, Nakamoto HA, Herson MR, Faes JC, Gemperli R, Ferreira MC. Tissue expander complications in plastic surgery: A 10-year experience. Revista do Hospital das Clínicas 2002;57:93-7.

9. Bozkurt A, Groger A, O'Dey D, et al. Retrospective analysis of tissue expansion in reconstructive burn surgery: Evaluation of complication rates. J Burns 2008;34:1113-8. 